\title{
ALGUNS DADOS SOBRE O COMPORTAMENTO PARASITOLÓGICO DAS LINHAGENS HUMANA E SILVESTRE DO SCHISTOSOMA MANSONI, NO VALE DO RIO PARAIBA DO SUL, SP (BRASIL)*
}

\author{
Othon de Carvalho Bastos * * \\ Luiz Augusto Magalhães*** \\ Humberto de Araújo Rangel *** \\ Aquiles Eugênico Piedrabuena ***
}

RSPUB $9 / 410$

Bastos, O. de C. et al. Alguns dados sobre o comportamento parasitológico das linhagens humana e silvestre do Schistosoma mansoni, no Vale do Rio Paraiba do Sul, SP (Brasil). Rev. Saúde públ., S. Paulo, 12:184-99, 1978.

RESUMO: Verificou-se ser elevada a percentagem de animais parasitados por $\mathrm{S}$. mansoni em roedores silvestres, de diferentes gêneros e espécies, capturados no Vale do Rio Paraiba do Sul, SP, Brasil onde se encontram com freqüência, casos humanos de esquistossomose mansônica. A partir de fígados de roedores naturalmente infectados foram obtidos miracidios para o isolamento da linhagem silvestre (S). Para o isolamento da linhagem humana $(H)$, foram utilizados miracidios procedentes de fezes de doentes comprovadamente autóctones do Vale do Rio Paraiba. Estudou-se, comparativamente, o comportamento das duas linhagens em B. tenagophila que é o hospedeiro intermediário natural na região e em camundongo albino, utilizado como hospedeiro definitivo. Verificoulse que: a taxa de mortalidade de $\mathrm{B}$. tenagophila infectadas com a linhagem " $\mathrm{S}$ " não $\dot{e}$, estatisticamente, diferente da dos moluscos utilizados para controle; $\dot{e}$ significativa a diferenca entre a taxa de mortalidade verificada nos moluscos infectados com a linhagem " $S$ " $e$ com a linhagem " $H$ ", a qual $\dot{e}$ consideravelmente maior nos moluscos infectados com a linhagem " $H$ "; nos camundongos infectados com a linhagem " $H$ " verificou-se ser significativo o coeficiente de correlação entre o número de granulomas hepáticos $e$ o de trematódeos adultos; nos camundongos infectados com a linhagem " $S$ " não houve possibilidade do estabelecimento de tal correleção.

Unitermos: Schistosoma mansoni. Roedores. Biomphalaria tenagophila.

INTRODU CQ

Há indicação de yue a esquistossonose inexistiam registros de casos humanos mansônica seja uma parasitose recentemen- autóctones nesta região. Além disso, a te implantda na região do Vale do Rio Biomphalaria tenagophila, única hospedeira Paraiba do Sul. Antes da década de 50, intermediária potencial encontrada no Vale,

* Trabalho realizado com o auxilio do CNPq e FAPESP.

* Da Universidade do Maranhão - Largo dos Amores, 66 - 65.000 São Luís. MA - Bolsista da FAPESP.

**** Do Instituto de Biologia da Universidade Estadual de Campinas (UNICAMP). Caixa Postal 1170. Campinas, SP - Brasil. 
BASTOS. $O$, de $C$. et al. Alguns datos sobre o comportamento parasitológico diss linhagens humana e silvestre do Schistosoma mansoni. no Vale do Rio Paraiba do Sul. SP (Brasil). Rer. Saude públ., S. Paulo. 12:184-99. 1978

mostrava-se resistente à infecção enı laboratório. Com o aparecimento dos primeiros doentes autóctones, intensificou-se a coleta de planorbideos, tendo sido descoberto 0 primeiro foco da doença, em 1956 (Corrêa e col. $)^{1 .}$. Nessa ocasiāo, várias tentativas foram feitas com o objetivo de infectar $B$. tenagophila experimentalmente, não se obtendo resultados positivos. Em 1963. Paraense e Corrêa : *an conseguiram infectar moluscos procedentes de Sáo José dos Campos, com miracidios pertencentes a linhagem mineira de $S$. mansoni, utilizando mil miracidios por molusco. Com estes resultados ficou comprovada a possibilidade da infecçāo dos moluscos "paulistas" com $S$. mansoni oriundo de $B$. glabrata de Minas Gerais, ainda que para isto tenha sido necessário o emprego de numero elevado de miracídios por molusco.

Os indices da infecção experimental da B. tenagophila do Vale do Rio Paraíba do Sul com a linhagem local, eram por outro lado, sempre inferiores aus obtidos pela infecçāo de $B$. glabrata de Minas Gerais com a linhagem de esquistossoma de Belo Horizonte. Estes fatos sugerem a pussibilidade de que a esquistossomose tenha sido introduzida no Vale do Rio Paraiba do Sul por migrantes de Minas Gerais.

Verificou-se, pelo trabalho de Cameronit (1928) e Kuntz $\approx$ (1952), yue o homen não é o único hospedeiro definitivo do helminto. Cameron encontrou cinco macacos africanos (Cercopithecus sabeus) naturalmente infectados, em zonas endêmicas de esquistossomose mansônica, na ilha de Sta. Kittz, Indias Ocidentais. Kuntz assinalou a presença de roedores (Gerbillus pyramidum) naturalmente infectados pelo verme, no Egito. Fenwick 1 (1969) descreveu a manutenção do ciclo biológico do parasita em comunidade de macacos (Papio anubis), na ausência do homem.

Devemus a Amorim 1 (1953), o primeiro encontro de roedores silvestres naturalmente infectados com Schistosoma mansoni, no Brasil. Embora muitos outros trabalhos sobre o tema tenham sido publicados em nosso pais (Amorim e col.2, 1954 e Amorim 3.4 1962; Barbosa e col.'.7, 1953, 1958; Barreto, 1959; Luz e col.2. 1966, 1967; Martins,"- 1958; Martins e col.,." 1955; Rodrigues e Ferreira, $3:$ 1969) e no exterior, o papel destes reservatórios naturais, na epidemiologia da endemia, permanecia sem conclusōes definitivas. Em 1971, Antunes." demonstrou ser possivel completar o ciclo do Schistosoma mansoni em roedor silvestre, usando para isto o sistema Nectomy's Biomphalaria glabrata - Nectomys.

Em 1972, Dias e col.1" e, em 1976 Dias '. assinalaram a presença, no Vale, de diferentes espécies de roedores silvestres naturalmente infectados com $S$. mansoni.

Após a verificação da manutenção do ciclo do Schistosoma mansoni na natureza, na ausência $d o$ homem, cabe formular a hipotese de yue ocorra duas linhagens de Schisosoma mansoni, una própria dos animais reservatorios e outra do homem e que os esquistossomos, oriundos dessas linhagens humana e silvestre, comportar-sejam de forma diversa frente a um hospedeiro definitivo comum (Mus musculus) e a um intermediário, também comum (Biomphalaria tenagophila).

O estudo destas linhagens forneceria novos dados referentes à relação parasitahospedeiro, no momento en que acreditamos estarmos assistindo ao inicio de um processo de adaptação do S. mansoni a $B$. tenagophila.

\section{MATERIAL E METODOS}

A captura de roedores silvestre foi teita no periodo noturno, em armadilhas colocadas ao nivel do solo, contendo iscas apropriadas. A positividade para S. mansoni, foi constatada nas fezes dos roedores, através da ovohelmintoscopia.

Para a exposição aos miracidios procedentes das linhagens humana $(H)$ e silvestre (S) do S. mansoni, foram utilizadas Biomphalaria tenagophila nascidas em labo- 
BASTOS, $O$, de $C$. et al. Alguns dados sobre o comportamento parasitológico das linhagens humana e silvestre do Schistosoma mansoni, no Vale do Rio Paraiba do Sul, SP (Brasil). Rer. Saude públ., S. Paulo, 12:184-99. 1978.

ratório, medindo de 8 a $12 \mathrm{~mm}$ de diâmetro, descendentes de planorbideos colhidos no campo, na região do Vale do Rio Paraíba.

Foram utilizados, como hospedeiros definitivos do S. mansoni, camundongos albinos, pesando aproximadamente 14 a $16 \mathrm{~g}$.

Para a obtenção de soros anti-S. mansoni, foram utilizados coethos.

A linhagem $\mathrm{H}$ do $S$. mansoni foi isolada a partir de miracídios obtidos de dejeções de doentes comprovadamente autóctones da região do Vale do Rio Paraiba.

As fezes coletadas na região eram transportadas para o laboratório em recipientes fechados, em completa ausência de luz e em baixa temperatura $\left(4^{\circ} \mathrm{C}\right)$.

No laboratório, as dejeções foram diluídas $(1 \mathrm{mg} / \mathrm{ml})$ em água não clorada, filtradas en gaze e deixadas sedimentar no escuro, por duas horas. O líquido sobrenadante era decantado e o sedimento ressuspenso em $50 \mathrm{ml}$ de água. A sedimentação foi repetida e o sedimento ressuspenso no volume de água acima referido.

Os miracidios foram obtidos pela exposiçẫo da suspensão final à luz e à temperatura de $28^{\circ} \mathrm{C}$, provenientes de lâmpadas elétricas de 60 watts, colocadas à distância de $40 \mathrm{~cm}$, durante $60 \mathrm{~min}$. (Standen $: 5$, 1952).

O isolamento da linhagem $S$ do $S$. mansoni foi feito a partir de miracídios obtidos de figados de roedores silvestres, naturalmente infectados con Schistosoma mansoni. Os aninais infectados foram necropsiados e os fígados retirados, pesados e homogeneizados en liquidificadores, con água não clorada em baixa temperatura (aproximadamente $10^{\circ} \mathrm{C}$ ). Os homogeneizados foram coletados em frascos de sedimentação e deixados repousar no escuro, por duas horas. O sobrenadante foi desprezado e o sedimento ressuspenso em $50 \mathrm{ml}$ de água. A suspensão final foi colocada em placas de Petri e exposta à luz e à temperatura de $28^{\circ} \mathrm{C}$, provenientes de làmpadas elétricas (Standen, 1952). Os miracidios eclodidos eram observados em lupa estereoscópica.
Infeção de Biomphalaria tenagophila com miracidios procedentes das linhagens humana (H) e silvestre (S).

Foram utilizados dois tipos de exposição das $B$. tenagophila aos miracídios $\mathrm{H}$ e $\mathrm{S}$ : exposição individual padronizada e exposifá̃o em massa (Standen,35, 1952).

$\mathrm{Na}$ exposição individual padronizada, $\mathrm{f}(1-$ ram tomados 90 moluscos e formados 3 grupos de 30. Um destes grupos foi constituído por moluscos não expostos, sendo tomado como controle (C) e foi utilizado para determinação da percentagem de mortalidade dos moluscos não infectados. Os dois grupos restantes foram expostus, separadamente, aos miracídios $\mathrm{H}$ e S. Cada moluscos era colocado isoladamente, em placa de Petri de $3,5 \mathrm{~cm}$ de diâmetro e exposto a 15 miracídios contidos em $10 \mathrm{ml}$ de água, em presença de luz e temperatura de $28^{\circ} \mathrm{C}$, por 5 a 6 horas. Os moluscos, após a infecção, eram mantidos isolados, em $100 \mathrm{ml}$ de água e com alimentação contrulada. Estes animais foram observados durante 100 dias, determinando-se a percentagem de mortalidade, número de moluscos que eliminaram cercárias e numero de cercárias eliminadas.

Para exposição em massa dos moluscos aus miracidios $H$ e $S$, foi determinado, primeiramente, 0 numero de miracidios eclodidos. Lotes de caramujos foram expostos a miracídios $\mathrm{H}$ ou $\mathrm{S}$, mantendo-se uma proporção de 15 miracídios por molusco. Foi mantido o contato molusco-miracidios por 5 a 6 horas, em condições de luz e temperatura citadas por Standen:(1952). Os moluscos, após a infecçāo, foram mantidos em recipientes, observandose a média de 15 caramujos por açuário de vidro contendo $2.000 \mathrm{ml}$ de água $\mathrm{e}$ alimentação adequada. Estes moluscos foram observados durante 60 dias, com a finalidade de se verificar a eliminação de cercárias. A percentagem de mortalidade dos moluscus e o número de cercárias eliminadas foram determinados durante 0 período de observação. 
BASTOS, O. de C. et al. Alguns dacios sobre o comportamento parasitologico das linhagens humana e silvestre do Schistosoma mansoni, no Vale do Rio Paraíba do Sul, SP (Brasil). Rev. Saúde puibl., S. Paulo, 12:184-99, 1978.

Infecção de camundongos albinos com cercárias provenientes de $\mathrm{B}$. tenagophila infectadas com miracidios $H$ e $S$ do $\mathrm{S}$. mansoni

Decorridas 4 semanas, contadas a partir da data da exposição das $B$. tenagophila aus miracídios $\mathrm{H}$ e $\mathrm{S}$, os moluscos foram expostos à luz e à temperatura de $28^{\circ} \mathrm{C}$, por 3 a 4 horas, com a finalidade de obter cercárias (Pellegrino e Macedo, ${ }^{32}$ 1955). A presença destas larvas era observada através do uso de lupa estereoscópica.

Com as cercárias $\mathrm{H}$ e $\mathrm{S}$ obtidas, foram infectados camundongos albinos, utilizandose a via percutânea e empregou-se a técnica de imersão parcial do animal em água contendo cercária (Brener,10,12 1959, 1956), ou a de imergir somente a cauda do animal na suspensão cercariana (Oliver e Stirewalt, 28,1952 ; Stirewalt e Bronson, ${ }^{37} 1955$ e Barrios-Duran, ${ }^{9}$ 1955). Quando foi utilizada a técnica de imersão exclusiva da cauda do camundongo, foi usada uma concentração de 100 cercárias para $10 \mathrm{ml}$ de água. Quando se empregou a técnica de imersão parcial, a quantidade de cercária por camundongos foi de 100 a 150 .

Manutenfão das linhagens humana (H) $e$ silvestre (S) do S. mansoni em laboratório

Foi utilizado o sistema camundongo-planorbideo-camundongo, para a manutenção das linhagens $\mathrm{H}$ e $\mathrm{S}$ do $S$. mansoni em laboratório. Para a exposição dos planorbídeos à ambas as linhagens do $S$. mansoni foram utilizados miracidios obtidos à partir do homogeneizado de fígados de camundongos infectados. Cada molusco foi exposto a 15 miracídios, nas condições citadas por Standen ${ }^{35}$ (1952). Com as cercárias $\mathrm{H}$ e S obtidas (Pellegrino e Macedo ${ }^{32}$, 1955) foram infectados camundongos albinos, conforme técnica de imersão parcial do animal em água contendo cercárias (Brener, ${ }^{10}$ 1959).
Obtenção de esquistossomos adultos e contagem de granulomas hepáticos, em Mus musculus albinos experimentalmente infectados

Camundongos infectados com cercárias $\mathrm{H}$ ou $\mathrm{S}$ foram sacrificados entre 55 e 65 dias após a infecção. O sistema porta foi perfundido e exemplares de $S$. mansoni adultos foram retirados dos vasos mesentéricos e hepáticos (Yolles e col.,39 1947 e Brener, ${ }^{11}$ 1962). Esquistossomos foram também obtidos por esmagamento do fígado, entre lâminas de vidro (Standen, ${ }^{36} 1953$ e Hill,20 1956).

Os figados retirados dos camundongos infectados foram homogeneizados em água, na temperatura de aproximadamente $10^{\circ} \mathrm{C}$ e, logo após, colocados em placas de Petri, para contagem dos granulomas. A contagem dos granulomas foi feita em lupa estereoscópica, seguindo-se o método descrito por Pellegrino e Brener ${ }^{31}$ (1956) e Brener e col. $^{13}$ (1959).

\section{RESULTADOS}

Roedores silvestres caputurados no Vale do Rio Paraiba

A área de captura dos roedores silvestres, no Vale do Rio Paraiba, ficou compreendida entre os municipios de São José dos Campos e Pindamonhangaba.

Foram capturados exemplares de diferentes espécies (Tabela 1), num total de 63 roedores. Do total de animais capturados, $13(20,6 \%)$ apresentaram-se naturalmente infectados, conforme Tabela 2 , onde se acham também indicados 0 período de captura, a região e os gêneros dos roedores. Pode-se verificar que das espécies capturadas a que apresentou maior freqüência foi Nectomys squamipes squamipes, seguindose Holochilus brasiliensis leucogaster.

Infecçâo experimertal de $B$. teragophila com miracidios das linhagens humana $(H)$ e silvestre (S)

A percentagem de mortalidade dos moluscos infectados pela técnica de exposição 
BASTOS, O. de C. et al. Alguns dados sobre o comportamento parasitológico das linhagens humana e silvestre do Schistosoma mansoni, no Vale do Rio Paraíba do Sul, SP (Brasil). Rev. Saude públ., S. Paulo, 12:184-99, 1978.

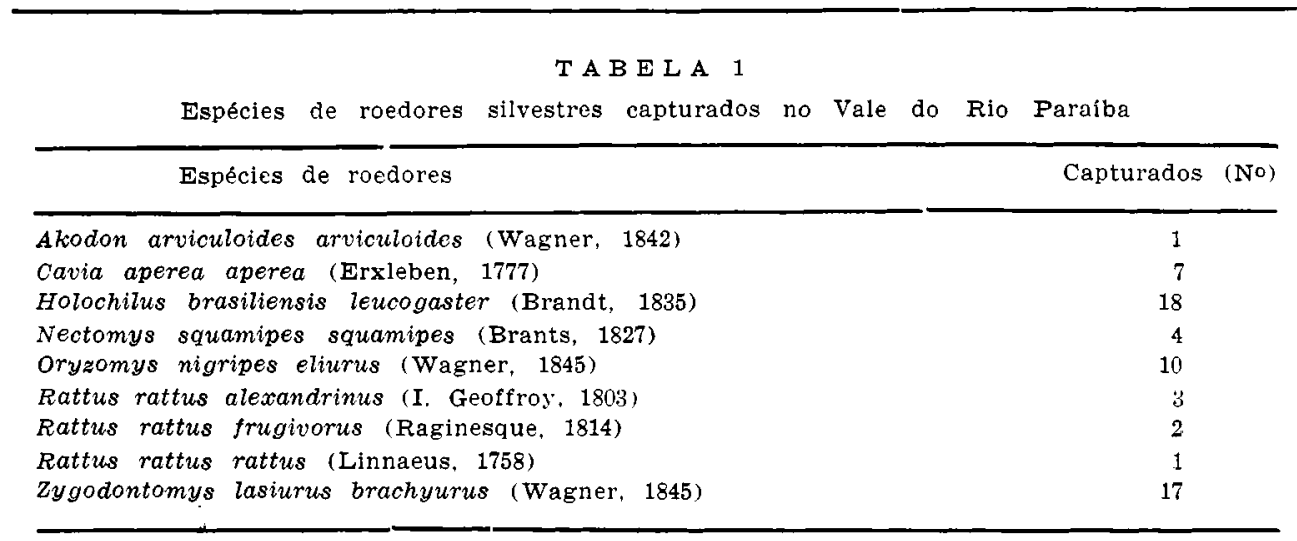

T A B E L A 2

Roedores silvestres capturados no Vale do Rio Paraiba

\begin{tabular}{|c|c|c|c|c|}
\hline Mês/Ano & Local de captura & Roedores & Capturados & Infectados \\
\hline $09 / 1972$ & Taubaté & Holochilus & 4 & 4 \\
\hline \multirow[t]{2}{*}{$10 / 1972$} & Taubaté & Zygodontomys & 1 & 1 \\
\hline & & Holochilus & 1 & 1 \\
\hline $11 / 1972$ & Taubaté & Holochilus & 1 & 1 \\
\hline \multirow[t]{12}{*}{$05 / 1973$} & S. Luís de Piratininga & Nectomys & 1 & 0 \\
\hline & Caçapava & Oryzomys & 1 & 0 \\
\hline & & Holochilus & 2 & 1 \\
\hline & & Zygodontomys & 1 & 0 \\
\hline & & Akodon & 1 & 0 \\
\hline & Pindamonhangaba & Oryzomys & 1 & 0 \\
\hline & & Cavia & 5 & 0 \\
\hline & & Zygodontomys & 1 & 0 \\
\hline & Taubaté & Cavia & 1 & 0 \\
\hline & & Holochilus & 1 & 0 \\
\hline & & Oryzomys & 4 & 0 \\
\hline & & Zygodontomys & 1 & 0 \\
\hline \multirow[t]{6}{*}{$08 / 1973$} & Caçapava & Zygodontomys & 1 & 0 \\
\hline & Taubaté & Oryzomys & 1 & 0 \\
\hline & & Rattus & 5 & 0 \\
\hline & Caçapara & Cavia & 1 & 0 \\
\hline & & Holochilus & 1 & 1 \\
\hline & Taubaté & Holochilus & 2 & 1 \\
\hline \multirow[t]{2}{*}{$11 / 1973$} & Caçapava & Holochilus & 1 & 0 \\
\hline & & Zygodontomys & 1 & 0 \\
\hline \multirow[t]{3}{*}{$05 / 1974$} & Caçapava & Nectomys & 3 & 3 \\
\hline & & zygodontomys & 8 & 0 \\
\hline & & Oryzomys & 2 & 0 \\
\hline \multirow[t]{3}{*}{$06 / 1974$} & Taubaté & Holochilus & 5 & 0 \\
\hline & & Zygodontomys & 2 & 0 \\
\hline & Pindamonhangaba & Rattus & 1 & 0 \\
\hline \multirow[t]{3}{*}{$07 / 1974$} & Taubaté & Zygodontomys & 1 & 0 \\
\hline & & Oryzomys & 1 & 0 \\
\hline & & Total & 63 & 13 \\
\hline
\end{tabular}


BASTOS, O. de C. et al. Alguns dados sobre a comportamento parasitológico das linhagens humana e silvestre do Schistosoma mansoni, no Vale do Rio Paraiba do Sul, SP (Brasil). Rev. Saúde puibl., S. Paulo, 12:184-99, 1978.

em massa e o número de cercárias eliminadas, foram determinados durante os primeiros 60 dias que se seguiram à infecção.

Os dados referentes às linhagens $\mathrm{S}$ e $\mathrm{H}$ estão apresentados nas Tabelas 3 e 4 , respectivamente. Pode-se verificar que a percentagem de mortalidade de caramujos, expostos aqs miracídios $\mathrm{S}$ e $\mathrm{H}$, foi alto para as duas linhagens. Verifica-se também que, dos 31 lotes expostos à linhagem $\mathrm{S}$, apenas 9 eliminaram cercárias. $\mathrm{Na}$ linhagem $H$, somente 6 lotes entre os 36 expostos, eliminaram cercárias. Nestas experiências não se observou relação entre o perodo do ano e a eliminação de cercárias.

T A B E L A 3

Percentagem de mortalidade em diferentes lotes de Biomphalaria tenagophila expostos a miracídios de Schistosoma mansoni da linhagem silvestre

\begin{tabular}{|c|c|c|c|c|}
\hline Lote & $\begin{array}{l}\text { Moluscos } \\
\text { expostos } \\
\text { (no) }\end{array}$ & $\begin{array}{l}\text { Mortalidade } \\
\text { após } 50 \text { dias } \\
(\%)\end{array}$ & $\begin{array}{l}\text { Cercárias } \\
\left(n^{\circ}\right)\end{array}$ & $\underset{\text { data }}{\text { Eliminadas }}$ \\
\hline 01 & 6 & 66,6 & 120 & março/1973 \\
\hline 02 & 15 & 94,0 & 14 & \\
\hline 03 & 16 & 62,5 & 120 & \\
\hline 04 & 22 & 68,1 & 0 & \\
\hline 05 & 5 & 100,0 & 0 & \\
\hline 06 & 20 & 300 & 3.420 & \\
\hline 07 & 5 & 100,0 & 0 & \\
\hline 08 & 5 & 60,0 & 0 & abril/1973 \\
\hline 09 & 11 & 45,4 & 1.600 & maio/1973 \\
\hline 10 & 8 & 12,5 & 0 & junho/1973 \\
\hline 11 & 5 & 100,0 & 0 & junho/1973 \\
\hline 12 & 12 & 85,0 & 50 & \\
\hline $1: 3$ & 21 & 27,2 & 180 & \\
\hline 14 & 5 & 100,0 & 0 & \\
\hline 15 & 14 & 100,0 & 0 & \\
\hline 16 & 6 & 83,3 & 0 & julho/1973 \\
\hline 17 & 20 & 90,0 & 500 & \\
\hline 18 & 35 & 97,1 & 0 & agosto $/ 1973$ \\
\hline 19 & 30 & 63,3 & 0 & \\
\hline 20 & 16 & 37,5 & 0 & \\
\hline $2 \pi$ & .25 & 57,4 & 0 & setembro/1973 \\
\hline 23 & 9 & 11,1 & 0 & \\
\hline 24 & 10 & 40,0 & 0 & \\
\hline 25 & 20 & 80,0 & 0 & novembro/1973 \\
\hline 26 & 20 & 90,0 & 0 & \\
\hline 27 & 10 & 80,0 & 0 & \\
\hline 28 & 10 & 60,0 & 0 & \\
\hline 29 & 5 & 40,0 & 0 & \\
\hline 30 & 20 & 90,0 & 0 & julho/1974 \\
\hline 31 & 10 & 60,0 & 0 & \\
\hline 32 & 5 & 60,0 & 4 & \\
\hline
\end{tabular}


BASTOS, O. de C. et al. Alguns dados sobre o comportamento parasitológico das linhagens humana e silvestre do Schistosoma mansoni, no Vale do Rio Paraíba do Sul, SP (Brasil). Rev. Saúde públ., S. Paulo, 12:184-99, 1978.

\begin{tabular}{|c|c|c|c|c|}
\hline \multicolumn{5}{|c|}{$\begin{array}{c}\text { TA B E A } 4 \\
\text { Percentagem de mortalidade em diferentes lotes de Biomphalaria tenagophila expostos } \\
\text { miracídios de Schistosoma mansoni da linhagem humana. }\end{array}$} \\
\hline Lote & $\begin{array}{l}\text { Moluscos } \\
\text { expostos } \\
\left(n^{\circ}\right)\end{array}$ & $\begin{array}{l}\text { Mortalidade } \\
\text { após } 50 \text { dias } \\
(\%)\end{array}$ & $\begin{array}{c}\text { Cercárias } \\
\text { (n०) }\end{array}$ & $\begin{array}{c}\text { Eliminadas } \\
\text { data }\end{array}$ \\
\hline 01 & 50 & 40,0 & 100 & março/1973 \\
\hline 02 & 20 & 25,0 & 248 & \\
\hline 03 & 20 & 10,0 & 350 & \\
\hline 04 & 50 & 64,0 & 5.320 & abril $/ 1973$ \\
\hline 05 & 5 & 20,0 & 0 & \\
\hline 06 & 6 & 50,0 & 0 & \\
\hline 07 & 5 & 60,0 & 0 & julho $/ 1973$ \\
\hline 08 & 5 & 100,0 & 0 & \\
\hline 09 & 15 & 80,0 & 0 & \\
\hline 10 & 30 & 86,6 & 0 & \\
\hline 11 & 15 & 93,3 & 0 & \\
\hline 12 & 25 & 100,0 & 0 & agosto $/ 197$ \\
\hline 13 & 30 & 90,0 & * & \\
\hline 14 & 10 & 70,0 & 100 & \\
\hline 16 & 10 & 75,0 & 0 & \\
\hline 17 & 20 & 40,0 & 0 & \\
\hline 18 & 12 & 100,0 & 0 & \\
\hline 19 & 16 & 12,5 & 0 & \\
\hline 20 & 17 & 29,4 & 0 & setembro/1973 \\
\hline 21 & 30 & 100,0 & 0 & \\
\hline 22 & 20 & 100,0 & 0 & \\
\hline 23 & 10 & 100,0 & 0 & dezembro/1973 \\
\hline 24 & 10 & 100,0 & 0 & \\
\hline 25 & 20 & 100,0 & 0 & \\
\hline 26 & 24 & 70,8 & 0 & fevereiro/1974 \\
\hline 27 & 8 & 87,5 & 0 & março/1974 \\
\hline 28 & 50 & 60,0 & 0 & \\
\hline 29 & 24 & 91,6 & 0 & abril $/ 1974$ \\
\hline 30 & 24 & 65,5 & 0 & \\
\hline 31 & 50 & 100,0 & $*$ & junho/1974 \\
\hline 32 & 45 & 46,6 & 210 & \\
\hline 33 & 14 & 50,0 & 0 & \\
\hline 34 & 33 & 42,4 & 0 & julho/1974 \\
\hline 35 & 50 & 48,0 & 0 & \\
\hline 36 & 8 & 37,5 & 0 & \\
\hline 37 & 6 & 33,3 & 0 & \\
\hline
\end{tabular}

* = desprezados

Os dados obtidos na exposição individual padronizada acham-se resumidos na Tabela 5 e Fig. 1. O grupo exposto à linhagem $\mathrm{H}$ apresentou percentagem de mortalidade nitidamente superior à do grupo controle $\mathrm{C}$, mostrando-se infectado aos $\mathbf{7 0}$ dias, quando 480 cercárias foram eliminadas por 3 moluscos. O lote de moluscos exposto à linhagem silvestre não apresentou mortalidade significativamente diferente da do grupo controle e apenas um dos moluscos eliminou cercárias, ao fim de 50 dias.

Pelo fato de termos obtido uma percentagem de mortalidade no grupo $C$ julgada elevada, repetimos a experiência utilizando novos moluscos conrtole e a mesma técnica 
BASTOS, O. de $C$. et al. Alguns dalos sobre o comportamento parasitológico das linhagens humana e silvestre do Schistosoma mansoni, no Vale do Rio Paraiba do Sul, SP (Brasil). Rev. Saúde públ., S. Paulo, 12:184-99. 1978.

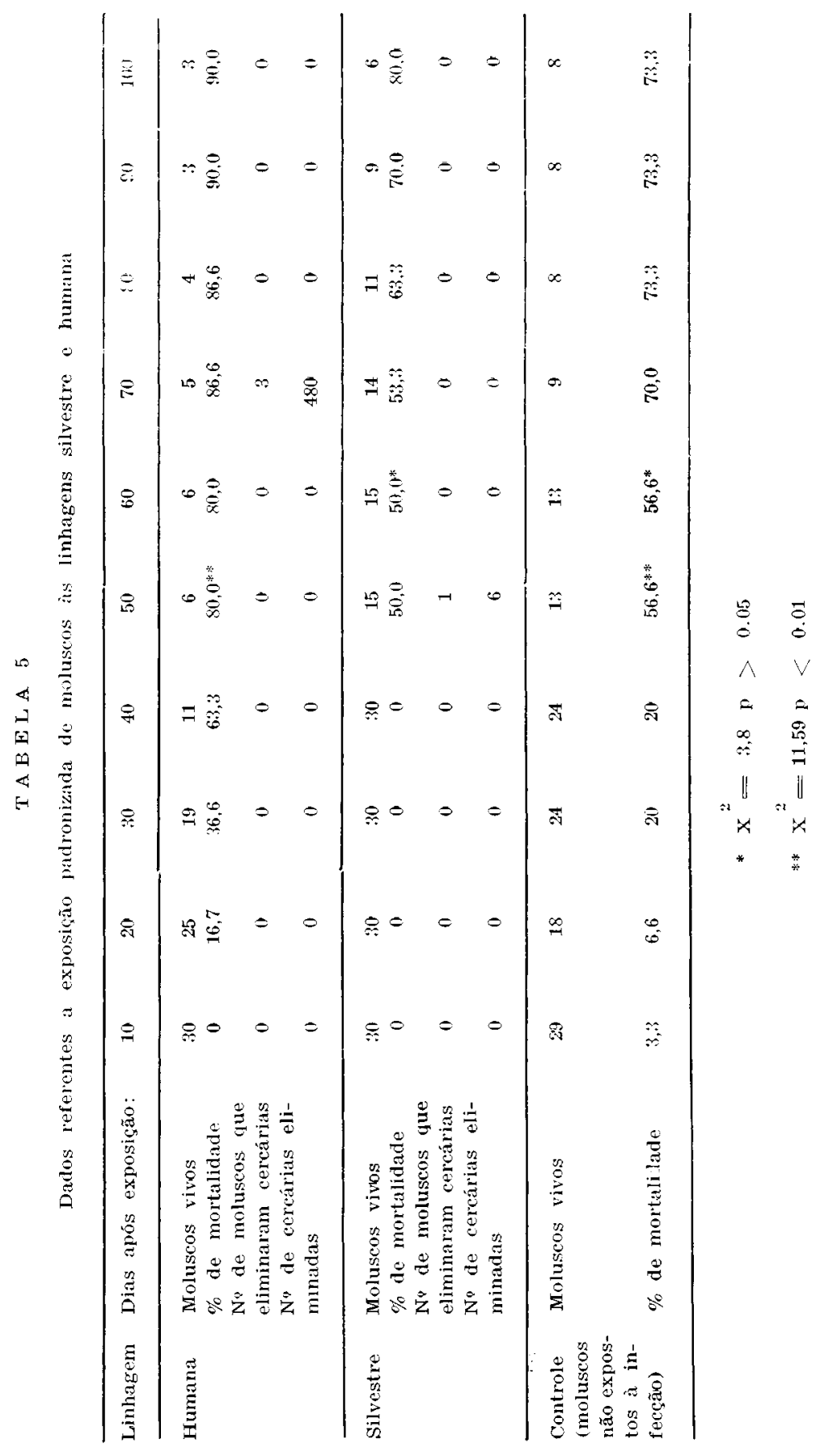


BASTOS, $O$, de $C$. et al. Alguns dados sobre o comportamento parasitológico das linhagens humana e silvestre do Schistosoma mansoni, no Vale do Rio Paraíba do Sul, SP (Brasil). Rev. Saúde públ., S. Paulo, 12:184-99, 1978.

\section{$\square$ Linhagem Humana de S.mansoni \\ $\triangle$ Linhagem Silvestre de S.mansoni \\ Contröle \\ Eliminação de cercárias}

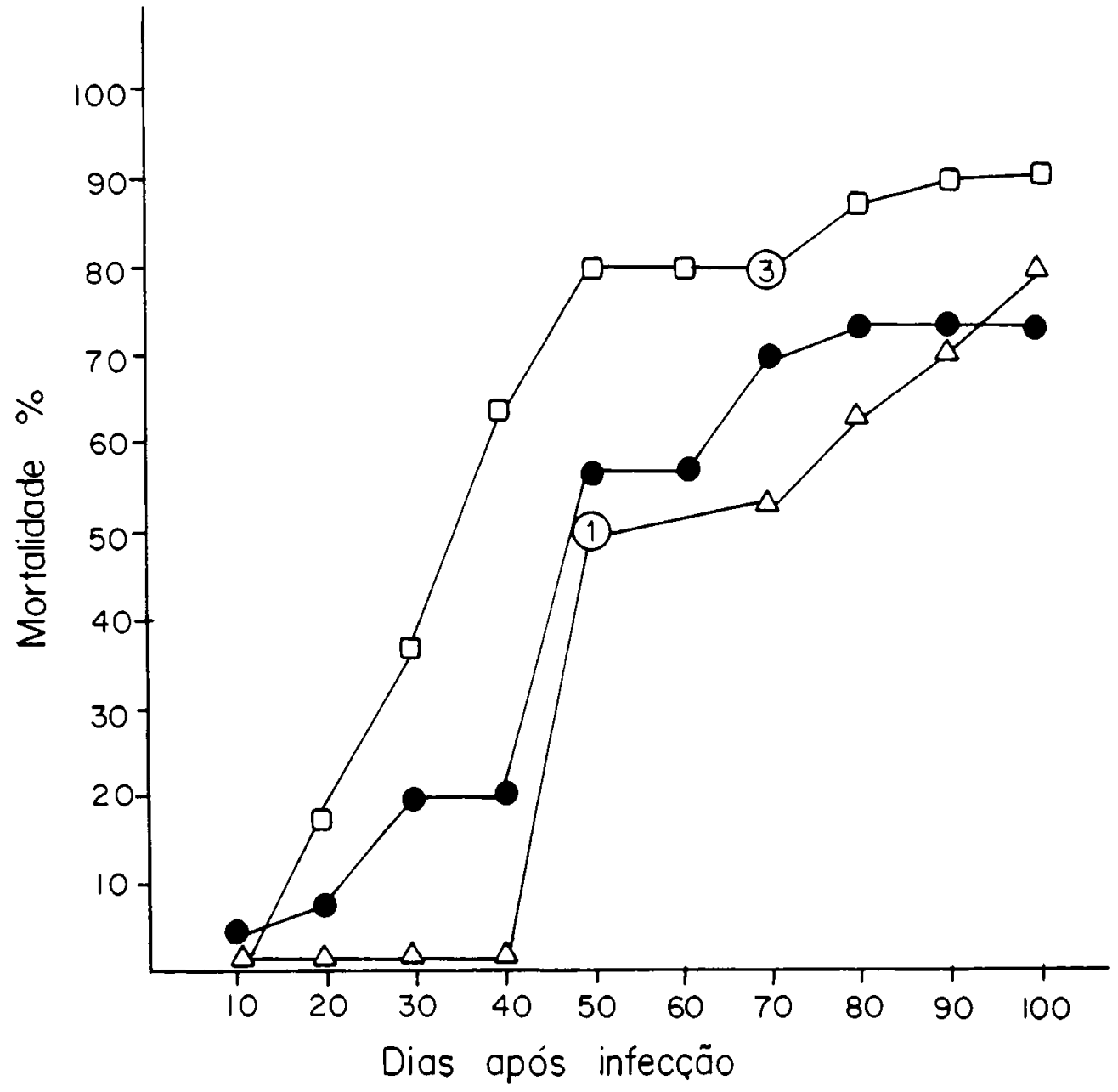

Fig. 1 - Curra de mortalidade após exposição de moluscos às linhagens humana e silvestre do Schistosoma marisoni 
BASTOS, $O$, de $C$. et al. Alguns da los sobre o comportamento parasitológico das linhagens humana e silvestre do Schislosoma mansoni, no Vale do Rio Paraíba do Sul, SP (Brasil). Rer. Saúde públ., S. Paulo. 12:184-99, 1978.

\section{T A B E L A 6}

Relação entre granulomas hepáticos e número de vermes obtidos de camundongos infectados com a linhagem humana

\begin{tabular}{|c|c|c|c|c|c|}
\hline \multicolumn{2}{|c|}{ Helmintos } & \multirow[b]{2}{*}{ Total } & \multirow{2}{*}{$\begin{array}{c}\text { Granulomas } \\
\times 1000\end{array}$} & \multirow{2}{*}{$\begin{array}{c}\text { Dias após a } \\
\text { inoculação }\end{array}$} & \multirow{2}{*}{$\begin{array}{l}\text { Relação } \\
\text { granulomas/vermes }\end{array}$} \\
\hline machos & fêmeas & & & & \\
\hline 85 & 75 & 150 & 4.8 & 55 & 32,4 \\
\hline 63 & 80 & 143 & 4.8 & 51 & 34,1 \\
\hline 81 & 53 & 134 & 5.6 & 51 & 42,2 \\
\hline 63 & 55 & 118 & 11.3 & 53 & 96,3 \\
\hline 56 & 46 & 102 & 4.3 & 51 & 42,4 \\
\hline 54 & 41 & 95 & 6.4 & 51 & 67,4 \\
\hline 44 & 38 & 82 & 8.0 & 53 & 97,8 \\
\hline 31 & 25 & 56 & 5.4 & 51 & 97,8 \\
\hline$: 35$ & 21 & 56 & 3.3 & 51 & 60,6 \\
\hline 22 & 2 & 24 & 2.5 & 53 & 106,1 \\
\hline $\bar{x}$ & 12 & 20 & 3.1 & 53 & 157,6 \\
\hline 12 & 2 & 14 & 1.8 & 53 & 131,4 \\
\hline 10 & 3 & 18 & 3.3 & 49 & 258,1 \\
\hline 5 & 1 & 6 & 1.8 & 53 & 302,5 \\
\hline 2 & 0 & 2 & 0.7 & 59 & 366,0 \\
\hline
\end{tabular}

T A B E L A 7

Relação entre granulomas hepáticos e número de vermes obtidos de camundongos infectados com a linhagem silvestre

\begin{tabular}{|c|c|c|c|c|c|}
\hline \multicolumn{2}{|c|}{ Helmintos } & Total & $\begin{array}{l}\text { Granulomas } \\
\times 1000\end{array}$ & $\begin{array}{l}\text { Dias após a } \\
\text { inoculação }\end{array}$ & $\begin{array}{c}\text { Relação } \\
\text { granulomas/vermes }\end{array}$ \\
\hline 118 & 50 & 168 & 2.8 & 56 & 16,7 \\
\hline 65 & 11 & 76 & $\therefore . z$ & 50 & 12,5 \\
\hline 34 & 34 & 68 & 5.5 & 50 & 81,6 \\
\hline 26 & 26 & 52 & 1.6 & 49 & 31,2 \\
\hline 41 & 9 & 50 & 4.2 & 50 & 85,3 \\
\hline 20 & 19 & 89 & 3.7 & 49 & 95.1 \\
\hline 17 & 17 & 34 & 6.5 & 50 & 192,9 \\
\hline 15 & 18 & 33 & 1.2 & 49 & 37,5 \\
\hline 15 & 12 & 27 & 2.4 & 49 & 89,6 \\
\hline 18 & 9 & 27 & 3.8 & 50 & 148,9 \\
\hline 12 & 4 & 16 & 2.1 & 50 & 137,1 \\
\hline 9 & 7 & 16 & 2.1 & 76 & 137,4 \\
\hline 8 & 8 & 16 & 4.3 & 76 & 274,8 \\
\hline 7 & 7 & 14 & 5.0 & 76 & 359,9 \\
\hline 5 & 5 & 10 & 4.2 & 76 & 427,4 \\
\hline 5 & 1 & 6 & 1.2 & 76 & 209,0 \\
\hline
\end{tabular}


BASTOS, O. de C. et al, Alguns dảos sobre o comportamento parasitológico das linhagens humana e silvestre do Schistosoma mansoni, no Vale do Rio Paraíba do Sul, SP (Brasil). Rev. Saúde públ., S. Paulo, 12:184-99, 1978.

T A B E L A 8

Arálise da correlação granulomas/no de vermes, para as linhagens humana e silvestre.

\begin{tabular}{lc|cc}
\hline \multicolumn{2}{c|}{ Linhagens: } & Humana & Silvestre \\
\hline Coeficiente de correlação & (r) & $0,65138^{* *}$ & 0,0064 \\
Coeficiente de regressão & (b) & 33,95633 & 0,26234 \\
Termo independente & (a) & 2.275 .82167 & $3.403,80964$ \\
\hline
\end{tabular}

** Significativo ao nível de $1 \%$

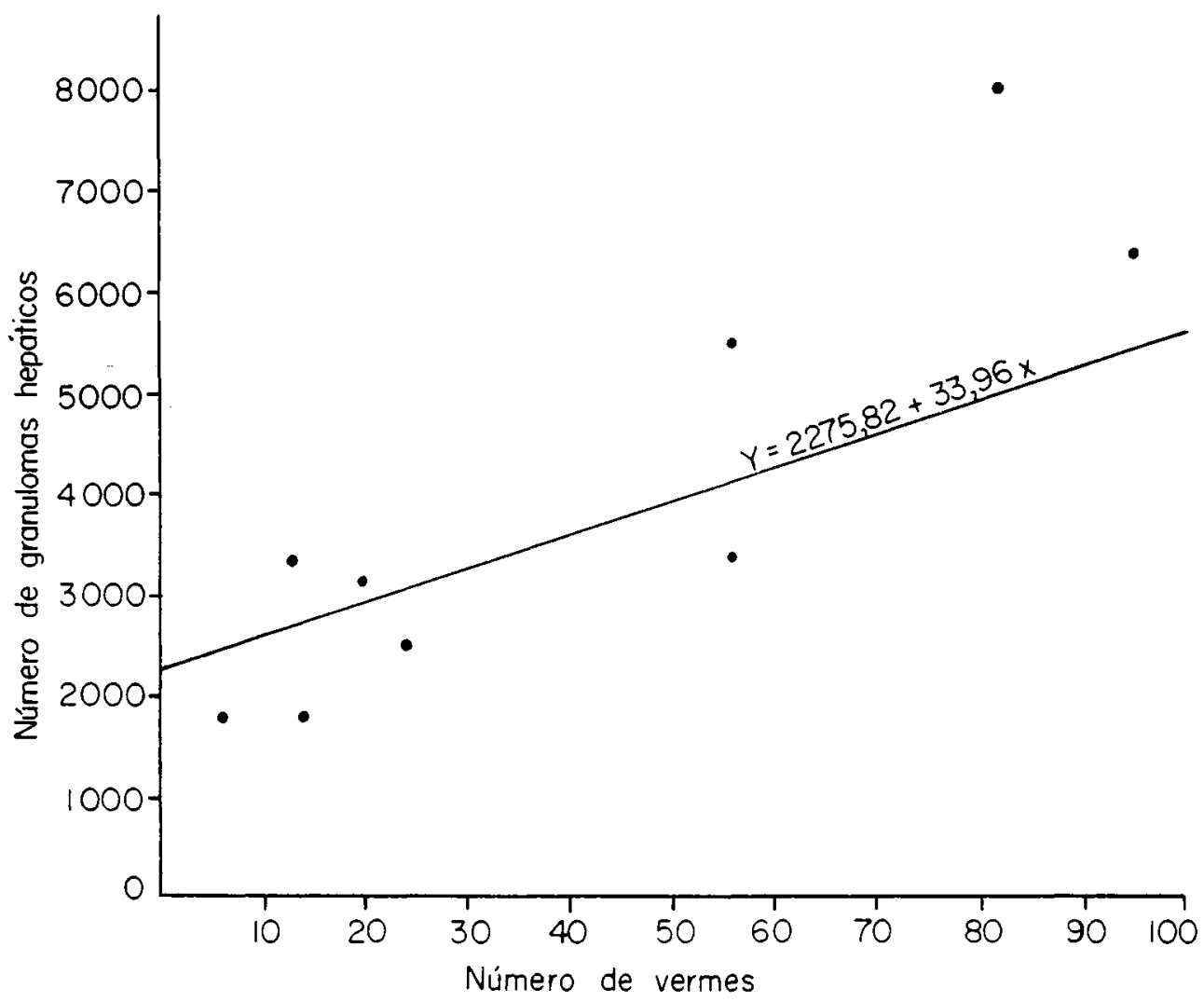

Fig. 2 - Correlação granulomas hepáticos/vermes obtida em camundongos infectados com Schistosoma mansoni da linhagem humana. 
BASTOS, O. de C. et al. Alguns dados sobre o comportamento parasitológico das linhagens humana e silvestre do Schistosoma mansoni, no Vale do Rio Paraiba do Sul, SP (Brasil). Rev. Saúde públ., S. Paulo, $12: 184-99,1978$.

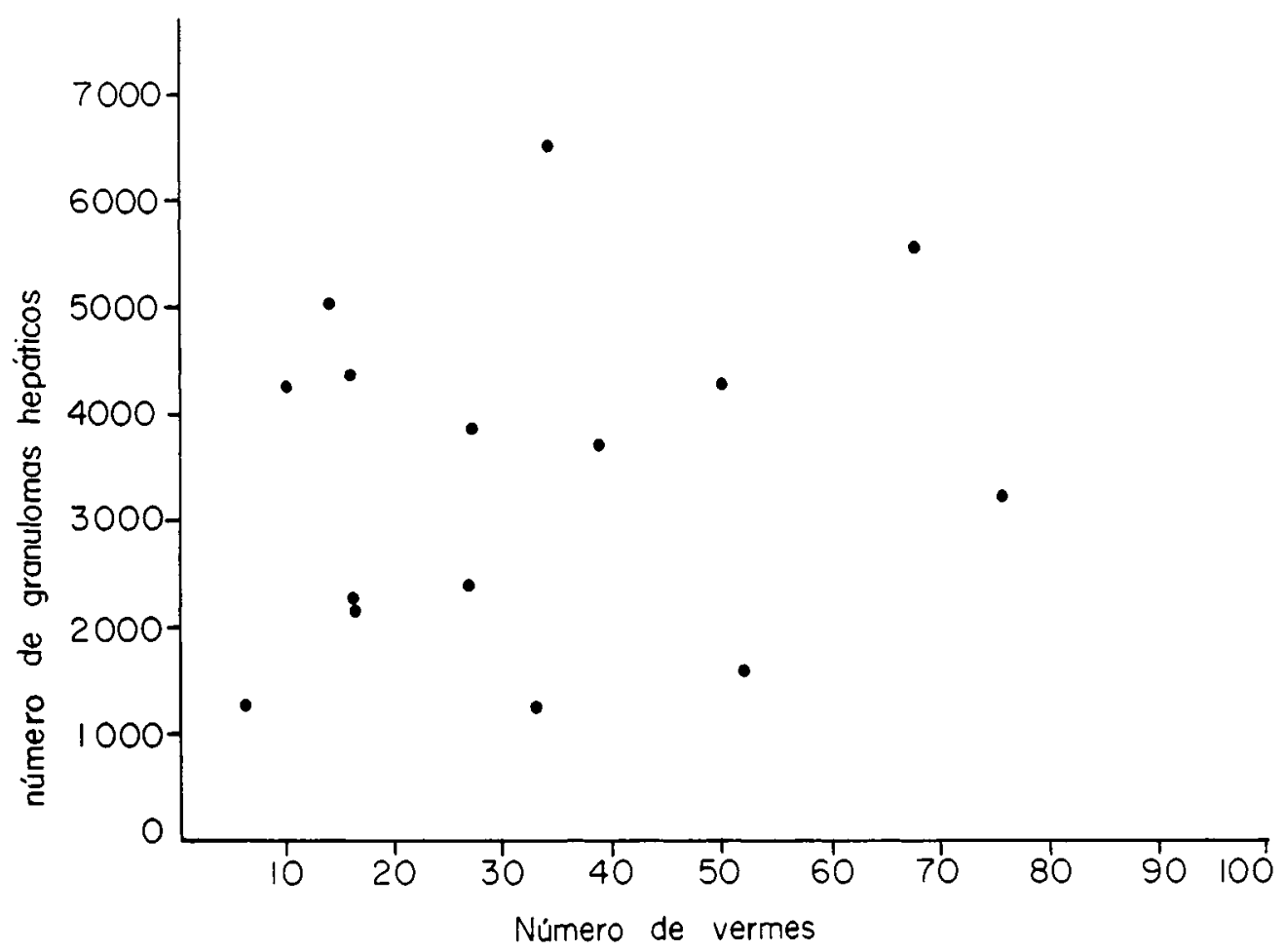

Fig. 3 - Correlação granulomas hepáticos/vermes obtida em camundongos infectados com Schistosoma mansoni de linhagem silvestre.

empregada anteriormente. Os novos resultados não diferiram significativamente dos obtidos anteriormente.

Estudo da relação granulomas-vermes nas linhagens humana e silvestre do $\mathrm{S}$. mansoni

A patogenicidade das linhagens humana e silvestre do $S$. mansoni foi estudada através das relações observadas entre os granulomas hepáticos e os vermes adultos encontrados na veia porta, mesentério e fígado de camundongos infectados com um número fixado de cercárias.

Os dados obtidos nestas experiências estão apresentados nas Tabelas 6 e 7 e Figs. 2 e 3 , onde se verifica que tanto o número de vermes como o número de gra- nulomas por animal teve amplas variações. A análise estatística da relação granulomasvermes, nas duas linhagens em estudo, acha-se apresentada na Tabela 8 , onde se verifica que foi possivel estabelecer um coeficiente de correlação significativo somente para os dados referentes a linhagem humana.

\section{DISCUSSAO}

Os roedores silvestres, capturados para o isolamento da linhagem $\mathrm{S}$, eram procedentes de diversas localidades, situadas às margens do Rio Paraíba do Sul. Entre os animais capturados, três espécies apresentaram-se naturalmente infectadas (Holochilus b. leucogaster, Nectomys s. squamipes e Zygodontomys l. brachyurus). Estas 
BASTOS, $O$. de C. et al. Alguns dalos sobre o comportamento parasitológico das linhagens humana e silvestre do Schistosoma mansoni, no Vale do Rio Paraíba do Sul, SP (Brasil). Rev. Saúde puibl., S. Paulo, 12:184-99, 1978.

espécies foram capturadas nos muricipios de Taubaté e Caçapava. Entre os animais capturados, Nectomys foi o gênero que, proporcionalmente, apresentou maior indice de infecção. Segundo Gilmour e Gregor ${ }^{19}$ (1969), o habitat dos animais deste gênero localiza-se em zonas suburbanas e rurais, quase sempre peridomiciliares (hortas e outras culturas). Esta observação reforça a hipótese de que o Nectomys desempenhe importante papel como reservatório natural do S. mansoni no Brasil, devido principalmente a frequiência com que é encontrado parasitado e a amplitude de sua distribuição (Amorin, $1953^{1}$ e $1962^{3,4}$; Amorim e col. ${ }^{2}$, 1954; Martins e col. ${ }^{25}$, 1955; Mooje, ${ }^{26}$ 1952; Martins,24 1958; Nelson,2i 1960; Antunes," 1971). As demais espécies de roedores, por nós encontradas parasitadas, são também consideradas importantes na epidemiologia da helmintose. Esta conclusão é baseada em fatos que parecem demonstrar o papel decisivo destes animais, na dispersão da doença. Assim é que, os roedores infectados foram encontrados em vasta área pesquisada e seus indices de infecção podem ser considerados elevados. Segundo Dias, ${ }^{16} 29,9 \%$ dos roedores capturados na região do Vale do Rio Paraíba apresentaram-se infectados com S. mansoni. Nossos resultados indicam um indice de infecção natural de $20,6 \%$, nos 63 roedores capturados.

No que se refere aos resultados obtidos com a infecção dos planorbídeos com as linhagens humana e silvestre, verificamos que os moluscos expostos à linhagem silvestre apresentaram mortalidade de $50 \%$ no $60^{\circ}$ dia após a data de exposição padronizada, enquanto que na linhagem humana, a mortalidade correspondente foi de $80 \%$. Esta alta mortalidade apresentada pela $B$. tenagophila, infectada pela linhagem $\mathrm{H}$, foi também encontrada por Magalhães ${ }^{23}$ (1969), quando trabalhou com esta mesma espécie de caramujo, infectada com S. mansoni de São José dos Campos. Este mesmo autor trabalhou com $B$. glabrata, infectada com S. mansoni da linhagem mineira e obteve bem menor mortalidade $(27,5 \%)$. Estes dados são coerentes com a hipótese que sugere adaptação recente do $S$. mansoni à $B$. tenagophila do Vale do Rio Paraiba.

A diferença encontrada entre a mortalidade, nos grupos de moluscos expostos à linhagem silvestre e no grupo controle, não foi significativa ( $p>0,05)$. A diferença entre a mortalidade obtida nos grupos de moluscos expostos à linhagem silvestre e à linhagem humana, foi significativa $(\mathrm{p}<0,01)$. Foi evidenciado, também, menor período de maturação dos esporocistos da linhagem silvestre. Estes fatos sugerem estar a linhagem $S$ mais adaptada a) hospedeiro intermediário do que a linhagem $\mathrm{H}$. Esta sugestão encontra apoio nos argumentos apresentados por Schwetz ${ }^{34}$ (1956), que admite ser a infecção esquistossomótica nos roedores anterior a do próprio homem. Schwetz observou em animais silvestres frequentes infeç̧ões crônicas, com baixa patogenicidade, podendo este fato indicar maior ađaptação hospedeiro-parasita.

A patogenicidade nos camundongos foi estudada através da relação granulomas/ vermes adultos. Escolhemos Mus musculus albinos como hospedeiro definitivo do $S$. mansoni devido a publicações anteriores que demonstraram a eficiência deste animal na manutenção das linhagens do verme Warren,40 1967; Taylor e Andrews, ${ }^{38}$ 1973). Como resultados destes experimentos, verificamos que houve relação causal significativa na linhagem humana, possibilitando um ajustamento linear, cuja função está apresentada na Fig. 2. Por outro lado, a linhagem silvestre não se comportou de maneira idêntica (Fig. 3). Acreditamos que esse resultado se deva ao fato de termos trabalhado com fígados oriundos de três espécies diferentes de roedores silvestres. naturalmente infectados.

\section{CONCLUSOES}

Diante dos resultados obtidos, pode-se concluir que: 
BASTOS, O. de C. et al. Alguns datos sobre o comportamento parasitológico das linhagens humana e silvestre do Schistosoma mansoni, no Vale do Rio Paraíba do Sul, SP (Brasil). Rev. Saúde puibl., S. Paulo, 12:184-99, 1978.

1 - As linhagens humana e silvestre do Schistosoma mansoni diferiram entre si quanto aos aspectos estudados do comportamento nos hospedeiros intermediários e definitivos.

2 - Parece existir dois ciclos paralelos do S. mansoni: um mantido pelo homem e outro mantido pelos roedores silvestres. Os roedores silvestres capturados apresentaram-se freqüentemente infectados e é provável que desempenhem papel importante na dispersão da esquistossomose mansônica no Vale do Rio Paraíba.

\section{AGRADECIMENTOS}

A Campanha de Combate à Esquistosomose da Secretaria da Saúde do Estado de São Paulo, através de sua Unidade localizada na Região, pela valiosa colaboração; ao Dr. Fernando de A'vila Pires, da Universidade Federal do Rio de Janeiro e Consultor da Organização Panamericana da Saúde, pela classificação dos animais silvestres.

RSPUB9/410

Bastos, $\mathrm{O}$. de $\mathrm{C}$. et al. /Some data on the parasitological behaviour of human $(H)$ and wild $(S)$ strains of S. Mansoni, in the Paraiba do Sul River Valley, State of São Patlo, Brazill Rev. Saúde públ., S. Paulo, 12:184-99, 1978 .

ABSTRACT: Human $(H)$ and wild (S) Schistosoma mansoni strains were obtained; the $H$ strain from eggs colected in human feces and the $S$ strain having its source in livers of several species of wild rodents. Results of the behaviour of these strains in Biomphalaria tenagophila and in albino Mus musculus are exposed in this work, summarized as follows: the mortality rate, statistically, did not differ in the group of infected snails and in the group of control snails; however, the difference between the mortality rates in snails infected with " $H$ " strain and with " $S$ " strain is significant; the mortality rate being higher in the molluscs infected with " $H$ " strain; in mice infected with " $H$ " strain a significant linear function between the number of hepatic granulomata and the number of adult worms was verified; in mice infected with " $S$ " strain it not was possible to establish such a correlation.

UNITERMS: Schistosoma mansoni. Rodents. Biomphalaria tenagophila.

\section{REFERENCIAS BIBLIOGRÁFICAS}

1. AMORIM. J. P. Infestação experimental e natural de murideos pelo Schistosoma mansoni (Nota prévia). Rev. bras. Malar., 5:219-22, 1953.

2. AMORIM, J. P. et al. Ratos silvestres, reservatórios do Schistosoma mansoni no Nordeste do Brasil. Rev. bras. Malar., 6:13-28, 1954.

3. AMORIM, J, P. Roedores silvestres como disseminadores de ovos de Schistosoma mansoni. Rev. Inst. Med. trop. S. Paulo, 4:397-402, 1962.
4. AMORIM, J. P. Infestação do homem e de roedores silvestres pelo Schistosoma mansoni em localidades do município de Viçosa (Estado de Alagoas, Brasil). Arq. Hig, S. Paulo, 27:335-9, 1962.

5. ANTUNES, C. M. de F. Nectomys squamipes squamipes Brants, 1827 na epidemiologia da esquistossomose mansoni. Belo Horizonte, 1971. [Dissertação de Mestrado - Instituto de Ciências Biologicas UFMG] 
BASTOS, O. de C. et al. Alguns dados sobre o comportamento parasitológico das linhagens humana e silvestre do Schistosoma mansoni, no Vale do Rio Paraiba do Sul, SP (Brasil). Rev. Saúde puibl., S. Paulo, 12:184-99, 1978.

6. BARBOSA, F. S. et al. Infestação natural de Ratius rattus frugivorus por Schistosoma mansori em Pernambuco. Publ. avuls. Irist. Aggeu Magalhães, 2:43-6, 1953.

7. BARBOSA, F. S. et al. Infestação natural e experimental de alguns mamiferos de Pernambuco por Schistosoma mansoni. Rev. bras. Malar., 10:137-44, 1958

8. BARRETO, A. C. Infestacão natural de rato de esgoto (Rattus norvegicus) por Schistosoma mansoni na cidade de Salvalor, Bahia. Bol. Fund. Goncalo Muniz, 14:1-5, 1959.

9. BARRIOS-DURAN, L. A. An efficient device for exposing mice to Schistosomo cercariae and holding small animal for post-morten examination. J. Parasit., $41: 641-2,1955$.

10. BRENER, Z. Esquistossomose experimental. Rev. bras. Malar., 11:473-506, 1959

11. BRENER, Z. Contribuição ao estudo da terapêtica experimental da esquistosomose mansónica. Belo Horizonte, 1962. [Tese de Cátedra - Faculdade de Odontologia e Farmácia da Universidade de Minas Gerais]

12. BRENER, $Z$, Observações sobre a infecção do camundongo pelo $S$. mansoni. Rev. bras. Malar., 8:565-70, 1956.

13. BRENER, $\boldsymbol{z}$. et al. Terapêutica experimental da Esquistossomose mansoni. Aplicação do método de isolamento de granulomas do figado de camundongos. Rev. bras. Malar., 8:583-7, 1956.

14. CAMERON, T. W. M. A new definitive host for Schistosoma mansoni. J. Helminth., 6:219-22, 1928 .

15. CORRA, R. R. et al. Um foco autóctone de esquistossomose no Vale do Paraíba. Folia clín. biol., S. Paulo, 26:85-90, 1956.

16. DIAS, L. C. de S. Aspectos parasitológicos e ecologicos de esquistossomose mansônica no Vale do Rio Paraíba do Sul e na Represa de Americana, Estado de São Paulo, Brasil. São Paulo, 1976. [Tese de Doutoramento - Instituto de Biologia da Universidade Estadual de Campinas]

17. DIAS. L. C. de $S$. et al. Roedores silvestres haspedeiros definitivos do Schistosoma mansoni. Rev. paul. Med. 79:99. 1972
18. FENWICK, A. Baboons as reservoirs host of Schistosoma mansoni. Trans, roy. Soc. trop. Med. Hyg., 63:557-67, 1969

19. GILMOUR, J. S. L. \& GREGOR, J. W. Demes: a suggested new terminology. Nature, 144:333, 1939 .

20. HILL, J. Chemoterapeutic studies with laboratory infections of Schistosoma mansoni. Arm. trop. Med. Parasit. $50: 39-48,1956$.

21. KUNTZ, R. E. Natural infection of an Egyptian gerbil with Schistosoma mansoni. Proc. helminth. Soc. Wash., $19: 123-4,1952$.

22. LUZ, E. et al. Reservatórios silvestres de Schistosoma mansoni numa área endêmica de esquistossomose no Estado do Paraná. An. Fac. Med. Univ. Fed. Parana, 9/10:113-20, 1966/67.

23. Magalhães, L. A. Estudo dos dados obtidos de uma população de Biomphalaria glabrata de Belo Horizonte infectada com Schistosoma mansoni da mesma cidade, e de uma população de $B$. tenagophila de Campinas, infectada por $S$. mansoni de São José dos Campos. Rev. Soc. bras. Med. trop. $3: 195-6,1969$.

24. MARTINS, A. V. Non human vertebrate host of Sohistosoma haematobium and Schistosoma mansoni. Bull. Wld Hlth Org.. 18:981-44, 1958.

25. MARTINS, A. V. et al. Reservatórios silvestres do Schistosoma mansoni no Estado de Minas Gerais. Rev. bras. Malar, 7:259-65, 1955.

26. MOOJEN, J, Os roedores do Brasil. Rio de Janeiro, Ministério da Educação e Saúde / Instituto Nacional do Livro, 1952.

27. NELSON, G. S. Schistosoma infections as zoonozes in Africa. Trans, roy. Soc trop. Med. Hyg., 54:301-16, 1960.

28. OLIVER, L. \& STIREWAIT, M. A. An efficient method for exposure of mice to cercariae of Schistosoma mansoni. J. Parasit., 38:19-23, 1952.

29. PARAENSE, W. L, \& CORREA, I, R. Sobre a ocorrência de duas raças biológicas do Schistosoma mansoni no Brasil. [Apresentado a 15a Reunião da Sociedade Brasileira para o Progrosso da Ciência. Campinas, 1963] 
BASTOS, $O$. de $C$. et al. Alguns dados sobre o comportamento parasitológico das linhagens humana e silvestre do Schistosoma mansoni, no Vale do Rio Paraíba do Sul, SP (Brasil). Rev. Saúde pübl., S. Paulo, 12:184-99, 1978.

30. Paraense, W. L. \& CORREA, L. R. Susceptibility of Australorbis tenagophilus to infection with Schistosoma mansoni, Rev. Inst. Med. trop. S. Paulo, 5:23-9, 1963.

31. PELlegrino, J. \& BRENER, Z. Method for isolating schistosoma granulomas from Mouse liver. J. Parasit., 42:564. 1956. [reprint]

32. PELlegrino, J. \& MACEDo, D. G. A simplified method for the concentration of cercariae. J. Parasit., 41 : 329-30, 1955.

33. RODRIGUES, D. C. \& FERREIRA, C. S Primeiro encontro de roedor (Nectomys squamipes) naturalmente infestado pelo Schistosoma mansoni, no Estado de São Paulo (Brasil). Rev. Inst. Med. trop. S. Paulo, 11:306-8, 1969.

34. SCHWETZ, J. Role of wild rats and domestic rats (Rattus rattus) in schistosomiasis of man. Trans. roy. Soc. trop. Med. Hyg., 50:275-82, 1956.

35. STANDEN, O. D. Experimental infection of Australorbis glabratus with $\mathrm{S}$. mansoni. I. Individual and mass infection to temperature and season. Ann. trop. Med. Parasit., 46:48-53, 1952.
36. STANDEN, O. D. The relationship of sex in $S$. mansoni to injection within the hepatic port system of experimentally infected mice. Ank, trop. Med. Parasit., 47:139-45, 1953.

37. STIREWALT, M. A. \& BRONSON, J. F. Description of a plastic mouse restraming case. J. Parasit., 41:328, 1955.

38. TAYLOR, M. G, \& ANDREWS, J, B. Comparison of the infectivity and pathogenicity of six species of African Schistosomos and their Hybrids. 1 Mice and hamsters. J. Helmint, 47: 439-53, 1973.

39. YOLLES, $\mathbf{T}$, et al, A technique for the perfusion of laboratory animals for the recovery of schistossomos. $J$. Parasit., $33: 419-26,1947$.

40. WARREN, $K$. S. A comparison of Puerto Rican, Egyptian and Tanzanian strains of $\mathrm{S}$. mansoni in mice. Penetration of cercariae, maturation of Schistossomos and production of liver disease. Trans. roy. Soc. trop. Med. Hyg., 61:795-802, 1967 .

Recebido para publicacão em 09/09;19\%7 Aprovado para publicasão em 25/10/1977 